\title{
AS PRINCIPAIS OPERAÇÕES METODOLÓGICO-JURÍDICAS PROPOSTAS POR ROBERT ALEXY: DA SUBSUNÇÃO À COMPARAÇÃO
}

THE MAIN LEGAL METHODOLOGICAL OPERATIONS PROPOSED BY ROBERT ALEXY: FROM SUBSUMPTION TO COMPARISON

LAS PRINCIPALES OPERACIONES METODOLÓGICO JURIDICAS PROPUESTAS POR ROBERT ALEXY: DE LA SUBSUNCIÓN A LA COMPARACIÓN

\section{Fausto Santos de Morais ${ }^{1}$}

Resumo: Este trabalho, fundado em pesquisa de cunho bibliográfico, tem como objetivo contribuir à discussão sobre a efetivação dos Direitos Fundamentais, principalmente, no que diz respeito ao recurso ao princípio da proporcionalidade. Dessa maneira, apresenta-se o princípio da proporcionalidade como um recurso metodológico que visa esquematizar a argumentação jurídica, principalmente, pela construção de normas de Direitos Fundamentais aditadas ou atribuídas. Além da referida elucidação, outra novidade apresentada pelo trabalho é mostrar a conexão existente entre as três operações lógicas que orientam a aplicação do Direito na visão de Robert Alexy. Ressalta-se, assim, que se objetiva contribuir com a apuração conceitual e metodológica sobre a aplicação do Direito, considerando, para tanto, o problema da colisão entre princípios jurídicos e a jurisprudência como fonte do Direito.

1 Doutor em Direito. Docente do PPGD IMED. Pesquisador com apoio da Fundação Meridional. Advogado. E-mail: fausto.morais@imed.edu.br. 
Palavras-chave: Constituição. Direitos Fundamentais. Princípio da Proporcionalidade.

Abstract: This work, which is based on bibliographical research, aims to contribute to the discussion on the effectiveness of Constitutional Rights, especially concerning about the application of the principle of proportionality. The principle of proportionality is presented as a methodological resource that aims to esquematizar the legal reasoning, mainly through the construction of rules on aditadas or attributed Constitutional Rights. Apart from this elucidation, another goal is to show the connection between the three logical operations that guide the application of law by Robert Alexy. It is emphasized that the intention of this work is to contribute to conceptual and methodological research on the application of the law, considering, for which it focuses on the problem of the collision between legal principles and jurisprudence as a source of Law

Key-Words: Constitution. Constitutional Rights. Principle of Proportionality.

Resumen: Este trabajo, fundamentado en una investigación de cuño bibliográfico, tiene como objetivo contribuir a la discusión sobre la efectuación de los Derechos Fundamentales, principalmente en lo que se refiere al recurso al principio de la proporcionalidad. De esa manera, se presenta el principio de la proporcionalidad como un recurso metodológico que intenta esquematizar la argumentación jurídica, principalmente a través de la construcción de normas de Derechos Fundamentales añadidas o atribuidas. Además de la referida elucidación, otra novedad presentada por el trabajo es mostrar la conexión existente entre las tres operaciones lógicas que orientan la aplicación del Derecho desde el punto de vista de Robert Alexy. Se destaca así que el objetivo es contribuir con la comprobación conceptual y metodológica sobre la aplicación del Derecho, considerando para ello el problema de la colisión entre principios jurídicos y la jurisprudencia como fuente del Derecho.

Palabras clave: Constitución. Derechos Fundamentales. Principio de la Proporcionalidad. 


\section{INTRODUÇÃO}

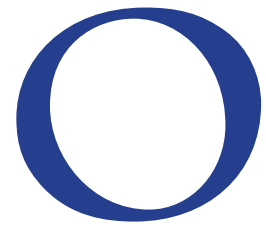

presente trabalho tem como objetivo apresentar as três metodologias que devem ser consideradas na aplicação do Direito a partir do marco teórico de Robert Alexy. Pretende-se, assim, mostrar a relação existente entre subsunção, ponderação e comparação (ou analogia). Num primeiro momento, o artigo oferece uma interpretação do princípio da proporcionalidade como constituidor de regras jurídicas que organizem a aplicação dos princípios jurídicos. Aliás, nessa oportunidade, será discutida a relação entre o princípio da proporcionalidade e a dogmática dos espaços de discricionariedade. Na sua segunda parte, apresentar-se-á a terceira operação metodológica na aplicação do Direito para Robert Alexy a comparação -, procurando ilustrar como que a relação entre subsunção, ponderação e comparação se dá.

Não se pode descurar que, com o estudo dessas questões, conforme propõe o presente artigo, pretende-se aprimorar o conhecimento quanto à utilização do princípio da proporcionalidade como forma de resolução dos problemas jurídicos que envolvem os direitos fundamentais. Isso porque, embora aparentemente a doutrina e a jurisprudência pátria utilizem o princípio da proporcionalidade em alusão à resolução dos conflitos entre princípios jurídicos - proposta teórica de Alexy -, na maioria das vezes a rigidez conceitual e metodológica apresentada pelo autor é desconsiderada, transformando a proporcionalidade em inexplicável (e irracional) recurso à resolução das questões sobre a aplicação do Direito ou aferição dos limites de restrição aos Direitos Fundamentais.

Alerta-se, desde já, que a presente discussão tem seu pressuposto nos "casos difíceis" - aqueles cujo sentido normativo não pode ser identificado diretamente ao texto constitucional, mas atribuído a ele -, em que a resolução do problema jurídico demandaria a consideração de mais de um princípio jurídico envolvido e, conforme apresentado, exigiria recorrer-se ao princípio da proporcionalidade como guia à harmonização da relação entre princípios. 
Diante disso, o artigo procura colaborar, mostrando a complexidade da teoria de Robert Alexy sobre a aplicação dos direitos fundamentais, principalmente o princípio da proporcionalidade como esquema metodológico. Para além, explorando a noção de analogia ou comparação, ideia decorrendo de um dos últimos trabalhos do autor, apresenta a imbricação existente entre as relações entre regras, princípios e precedentes - ou, de outra forma, subsunção, ponderação e comparação -, contribuindo para desmistificar o uso da proporcionalidade, ou ponderação, como recurso dissociado de outras metodologias de aplicação do Direito.

\section{O PRINCÍPIO DA PROPORCIONALIDADE DE SUAS DERIVAÇÕES METODOLÓGICAS}

O estudo da proposta de Robert Alexy apresenta a proporcionalidade como um sistema que coordena a aplicação e a fundamentação das normas de direitos fundamentais, mais precisamente, de princípios jurídicos, existindo, como sustenta o autor, algumas estruturas que devem ser consideradas para tanto.

Um dos primeiros passos a ser observados na aplicação da máxima da proporcionalidade, seria a verificação subsidiária das submáximas que a compõem. Assim, propõe-se denominar essa primeira estrutura de aplicação do sistema da proporcionalidade como a lei da subsidiariedade entre as máximas.

Portanto, sempre que um ato for analisado como válido a partir da proporcionalidade, será devido a sua submissão às submáximas referidas. Primeiro, ver-se-á se o ato é adequado. Depois, se é necessário. Após preenchimento desses dois requisitos, far-se-á a ponderação entre os princípios jurídicos envolvidos. $O$ mesmo aconteceria com os direitos a prestações, cujo exame da necessidade e da adequação estaria orientado pela eficiência e pelo sopesamento.

Eis a importância de conhecer o sopesamento. Para tanto, Alexy orienta o sopesar para a existência de uma lei, denominada lei de sopesamento². Essa estrutura compõe a máxima da proporcionalidade quando se procura analisar

2 Na verdade, seria possível indicar duas leis de sopesamento. A primeira, que colocaria em discussão o grau de satisfação e de intervenção, complementada pela segunda, que exigiria grande certeza das premissas sobre as premissas envolvidas. 
a terceira submáxima: a proporcionalidade em sentido estrito. Portanto, sempre que se estiver falando sobre a aplicação da proporcionalidade em sentido estrito, seria necessário observar a incidência da lei de sopesamento.

Faz-se necessário o seguinte esclarecimento: a lei de sopesamento é diferente da lei de colisão. A segunda diz respeito à forma lógica de ordenação da precedência entre os princípios jurídicos envolvidos. Quer dizer, determina a formulação da seguinte estrutura lógica: $\left(P_{1} P P_{2}\right) C .{ }^{3} N a$ verdade, não é forçoso entender que a formulação da regra de precedência entre os princípios jurídicos envolvidos em dado caso concreto implicaria a construção do suporte fático para aplicação da regra.

Nesse sentido, a equação de precedência $\left(\mathrm{P}_{1} \mathrm{P} \mathrm{P}_{2}\right) \mathrm{C}$ implica a consideração de condições fáticas e jurídicas do caso concreto como elementos constituidores do suporte fático $C\left(T_{1}\right.$ e $T_{2}$ e $T_{3}$ e $\left.T_{4}\right) \rightarrow R$.

A construção desse suporte fático dá aplicabilidade a uma regra específica que dilui a tensão entre diferentes princípios jurídicos perante o caso concreto que, numa situação inicial, envolvia a discussão sobre a tensão entre dois princípios produza uma regra que organize a relação entre eles. Essa regra, como já se viu, goza da estrutura lógica da subsunção. Eis a estrutura lógica apresentada por Alexy para a subsunção:4

$(\mathrm{x})(\mathrm{Tx} \rightarrow \mathrm{ORx})$

$(x)\left(M^{1} x \rightarrow T x\right)$

$(\mathrm{x})\left(\mathrm{M}^{2} \mathrm{x} \rightarrow \mathrm{M}^{1} \mathrm{x}\right)$

Afirma Alexy que a aplicação da regra mediante subsunção envolveria tanto a consideração da estrutura lógico-conceitual ${ }^{5}$ como recursos para esclarecer os passos

3 ALEXY, Robert. Teoria dos Direitos Fundamentais. Tradução de Virgilio Afonso da Silva. São Paulo: Malheiros Editores, 2008, p. 98.

4 ALEXY, Robert. On Balancing and Subsumption. A Structural Comparison. Ratio Juris, v.16. n. 4. Dec 2003, p. 433-449.

5 Mesmo quando Alexy fala em subsunção não ignora a necessidade de apresentação de razões que sustentassem essa operação lógica de forma argumentativa. Assim, mesmo quando se estivesse diante de casos fáceis, as premissas do raciocínio, as regras semânticas no uso dos conceitos utilizados e sua interligação aos casos, bem como a consistência 
lógicos-dedutivos entre as premissas utilizadas na dedução. Feito isso, o próximo passo seria, conforme o autor, exercer a justificação interna do silogismo. Não esquece o autor, contudo, as exigências de justificação interna e externa do silogismo. ${ }^{6}$

Construir essa regra de precedência, aplicada mediante a subsunção, requer o passo anterior que passa pela máxima da proporcionalidade. Isso porque seria o sopesamento a operação lógica anterior à construção dos elementos lógicos necessários à criação de uma regra de precedência aplicada mediante subsunção.

Falar em sopesamento é determinar a relação entre os princípios jurídicos envolvidos, considerando a seguinte lei (de sopesamento): "Quanto maior for o grau de não satisfação ou de afetação de um princípio, tanto maior terá que ser a importância da satisfação de outro".7

A lei supra pode ser correspondida por uma formulação lógica que considera a discussão concreta sobre a intervenção e a satisfação sobre os princípios jurídicos envolvidos $\left(\mathrm{P}_{1}\right.$ e $\left.\mathrm{P}_{2}\right)$. Assim, quanto:

à intervenção, compreende-se a fórmula: $\mathrm{IP}_{i} \mathrm{C}=\mathrm{P}_{1}$.

à satisfação, opera-se com a fórmula: $W P_{j} C=P_{2}$.

Entende Alexy que os graus de intervenção e satisfação poderiam ser avaliados gradualmente, considerando leves $(l)$, médios $(m)$ ou severos $(s)$. Aplicar a lei de sopesamento envolveria três passos, sendo os dois primeiros avaliação do grau de intervenção/satisfação entre os princípios jurídicos envolvidos. ${ }^{8}$

Num caso concreto, seria possível orientar a primeira lei de sopesamento por meio da seguinte fórmula: ${ }^{9}$

$\mathrm{GP}_{\mathrm{ij}} \mathrm{C}=\underline{\underline{\mathrm{IP}}} \underline{\mathrm{C}}_{\underline{\mathrm{C}}}$

WP $\mathrm{P}_{\mathrm{j}} \mathrm{C}$

do resultado, deveriam ser argumentativamente apresentadas. Cf. ALEXY, Robert. On Balancing and Subsumption. A Structural Comparison. p. 434.

6 Explica-se: mesmo acreditando na lógica deducionista, Alexy não deixa de lado a necessidade de justificação da operação de subsunção. Essa necessidade de justificação envolveria tanto o âmbito interno quanto externo.

7 ALEXY, Robert. Teoria dos Direitos Fundamentais. p. 167.

8 ALEXY, Robert. Teoria dos Direitos Fundamentais. p. 167.

9 ALEXY, Robert. Teoria dos Direitos Fundamentais. p. 167. 
Assim, a determinação do peso concreto dos princípios $\left(\mathrm{GP}_{\mathrm{ij}} \mathrm{C}\right)$ colocaria emjogo relações entre intervenção e satisfação entre os princípios jurídicos, considerando a atribuição de juízos de valor sobre a intensidade $(l, m, s)$. Essas relações poderiam determinar três tipos de resultados: a) precedência de $\mathrm{P}_{1}{ }^{10} ; \mathrm{b}$ ) preponderância de $\mathrm{P}_{2}{ }_{2}^{11} ; \mathrm{c}$ ) impasse na relação, em que seria reconhecida a discricionariedade do legislador e a impossibilidade de controle pelo poder judiciário - denominado por Alexy como espaço estrutural de discricionariedade ${ }^{12}$.

Essa pode ser considerada a primeira lei de sopesamento que possui associação à importância material das razões que sustentam a intervenção/satisfação (lei material do sopesamento). ${ }^{13}$ Isso porque, adicionalmente à ideia de afetação e satisfação entre os princípios jurídicos envolvidos, também se mostra necessário conhecer as condições epistêmicas envolvidas. O próprio Alexy reconhece na existência da segunda lei de sopesamento essa condição, indicando a seguinte relação: "Quanto mais pesada for a intervenção em um direito fundamental, tanto maior terá que ser a certeza das premissas nas quais essa intervenção se baseia". ${ }^{14}$ Alexy vai chamá-la de "Lei epistêmica de sopesamento". ${ }^{15}$

Tanto como os juízos sobre a intensidade de intervenção e satisfação dos princípios jurídicos relativos ao caso concreto, a lei epistêmica pode reconhecer diferentes níveis de certeza sobre os pressupostos empíricos envolvidos na aplicação do princípio da proporcionalidade. Assim, trabalhar-se-ia com as seguintes categorias sobre a plausibilidade ou evidência das questões empíricas: certo ou garantido $(g)$, sustentável ou plausível $(p)$ e não evidente ou falso $(e)^{16}$.

10 Seriam as três formulações em que $P_{1}$ deveria preponderar: (1) IP $C: S / W P_{j} C: I ;$ (2) $I_{i} C$ : s/ WP $\mathrm{C}_{\mathrm{j}}: m ;$ (3) IP $\mathrm{C}: \mathrm{m} / \mathrm{WP} \mathrm{C}_{\mathrm{j}} \mathrm{C}: /$. Cf. ALEXY, Robert. Teoria dos Direitos Fundamentais. p. 602 .

11 Também seriam de três as posibilidades de preponderância do $\mathrm{P}_{2}$ : (1) IP $\mathrm{C}:$ : / WP $\mathrm{P}_{\mathrm{j}} \mathrm{C}: s$; (2)

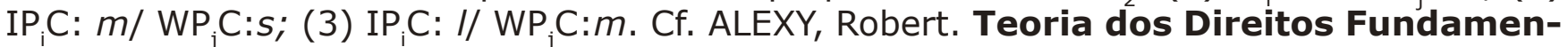
tais. p. 602 .

12 Nesse conjunto de possibildades, deveria ser considerada a discricionariedade estrutural $\left(P_{1}=P_{2}\right.$ : (1) IP $P_{i}$ : $/ / W_{p_{j}} C: / ;(2) I_{i} C: m / W P_{j} C: m ;(3) I_{i} C: s / W P_{j} C: s$. Nessas relações seria possível dizer que, ao mesmo tempo, poderia o legislador agir ou não, porque teria uma faculdade de discricionariedade. Isso porque o legislador não seria obrigado nem proibido pela Constituição a fazer ou deixar de fazer algo. ALEXY, Robert. Teoria dos Direitos Fundamentais. p. 608.

13 ALEXY, Robert. Teoria dos Direitos Fundamentais. p. 617.

14 ALEXY, Robert. Teoria dos Direitos Fundamentais. p. 617.

15 ALEXY, Robert. On Balancing and Subsumption. A Structural Comparison. p. 446.

16 Alexy vai designar o símbolo " $S$ " para apresentar a segurança das suposições empíricas 
Quando se pretende sopesar princípios jurídicos, em atenção à submáxima da proporcionalidade em sentido estrito, dever-se-ia levar em conta a determinação dessas duas leis de sopesamento, permitindo a construção da "Fórmula de Peso". Uma diz respeito à fundamentação da intervenção/satisfação entre os princípios. A segunda, àquilo que envolve a certeza empírica sobre esses juízos de intervenção e satisfação.

Observando a proposta de Alexy, a Fórmula de Peso poderia ser representada pela seguinte estrutura ${ }^{17}$ :

$$
\begin{aligned}
& \mathrm{GP}_{\mathrm{ij}} \mathrm{C}=\underline{\mathrm{IP}}_{\mathrm{i}} \mathrm{C}-\mathrm{SP} \mathrm{P}_{\mathrm{i}} \mathrm{C} \\
& W P_{j} \mathrm{C}-\mathrm{SP}_{\mathrm{j}} \mathrm{C}
\end{aligned}
$$

A importância da Fórmula de Peso, considerando a contribuição da "Lei de sopesamento epistêmica", envolveria o fato de que o grau de incerteza na satisfação de um determinado princípio jurídico determinasse maior peso à impossibilidade de intervenção no princípio colidente. Da mesma forma, quanto maior a certeza da satisfação do princípio jurídico envolvido, maior seria a possibilidade de intervenção no princípio adversário.

A partir da análise quanto às leis de sopesamento, Alexy desenvolve uma dogmática dos espaços de discricionariedade legislativa. ${ }^{18} \mathrm{O}$ que isso quer dizer? Que o Poder Judiciário não seria legítimo para controlar as decisões do legislador nas circunstâncias de espaço estrutural e espaço epistêmico. ${ }^{19}$

Os espaços estruturais, ou discricionariedade/margem de conformação do

envolvidas. Assim, a equação da segurança que deveria ser considerada pelo sopesamento seria: "SP $\mathrm{C}_{\mathrm{i}}$ e "SP $\mathrm{C}_{\mathrm{i}}$ ". Cf. ALEXY, Robert. Teoria dos Direitos Fundamentais. p. 619. Assim, estar-se-ia considerando três diferentes níveis de segurança sobre as premissas empíricas consideradas, sendo elas: certas ou confiáveis, plausíveis ou não evidentemente falsas. Adotar uma dessas classificações sobre as certezas empíricas determinaria a atribuição de certo valor ou peso a um dos "princípios" discutidos.

17 Essa é a fórmula na sua versão simplificada. Tal característica se dá por deixar de fora a discussão sobre o peso abstrato dos princípios jurídicos envolvidos. Cf. ALEXY, Robert. Teoria dos Direitos Fundamentais. p. 604.

18 GAVIÃO FILHO, Anizio Pires. Colisão de direitos fundamentais, argumentação e ponderação. Porto Alegre: Livraria do Advogado Editora, 2011, p. 301.

19 ALEXY, Robert. Direito constitucional e direito ordinário - jurisdição constitucional e jurisdição especializada. In: ALEXY, Robert. Constitucionalismo discursivo. Tradução Luís Afonso Heck. Porto Alegre: Livraria do Advogado Editora, 2007a, p. 71-92. 
legislador, estariam ligados à determinação da finalidade ${ }^{20}$, à escolha do meio ${ }^{21}$ e à ponderação 22 sempre que a norma constitucional não fosse definitiva em proibir ou ordenar. Haveria uma faculdade proporcional ao legislador. Isto é, ele teria a faculdade de decidir desde que o imperativo da proporcionalidade não fosse violado, caso em que, por exemplo, quando o sopesamento levasse a empates, como visto anteriormente.

Em espaços epistêmicos, estaria presente a inexigibilidade, um conhecimento do legislador maior que aquele cognitivamente possível. O que equivale a dizer que o legislador poderia assumir como premissas conhecimentos empíricos e normativos não ordenados nem proibidos pela Constituição, conferindo ao legislador discricionariedade diante da incerteza. ${ }^{23}$ Um dos exemplos pensáveis é a prognose ao legislador. Por via de regra, os espaços de cognição empírica seguiriam a ordem da segunda lei de sopesamento. Assim, quanto maior a restrição do direito fundamental, maior deveria ser a segurança empírica e normativa das premissas. ${ }^{24}$

Parece que a compreensão dos espaços de discricionariedade pelo legislador pode ser verificada pela aplicação das leis de sopesamentos. Se não for possível dizer o que é proibido ou ordenado, e considerando a hipótese de impasse, teria o legislador o poder de decidir sem a possibilidade de controle do Poder Judiciário.

Acredita-se ser possível exemplificar a aplicação das duas fórmulas tratadas (subsunção e sopesamento), por meio do caso Lebach (BVerfGE 35, 202), explorado por Robert Alexy. O caso envolvia o direito de liberdade de informar por radiofusão $\left(P_{1}\right)$ um documentário sobre os crimes praticados por Lebach. O problema seria que tal ato implicaria a lesão ao direito de proteção

20 Estaria o legislador autorizado pela Constituição escolher uma finalidade e a medida de sua realização. Cf. ALEXY, Robert. Direito constitucional e direito ordinário - jurisdição constitucional e jurisdição especializada. p. 80.

21 Teria o legislador o poder para escolher o meio entre vários igualmente idôneos. Cf. ALEXY, Robert. Direito constitucional e direito ordinário - jurisdição constitucional e jurisdição especializada. p. 80.

22 Já foi tratado no trabalho e representa a impossibilidade de dizer que um princípio teria afetado desproporcionalmente - no sentido de uma intensidade não justificada pela primeira e segunda lei de sopesamento. Cf. ALEXY, Robert. Direito constitucional e direito ordinário - jurisdição constitucional e jurisdição especializada. p. 80.

23 ALEXY, Robert. Teoria dos Direitos Fundamentais. p. 89.

24 GAVIÃO FILHO, Anizio Pires. Colisão de direitos fundamentais, argumentação e ponderação. p. 307. 
à personalidade $\left(\mathrm{P}_{2}\right)$. A decisão do Tribunal Constitucional Federal alemão foi de, no caso concreto, proibir a exibição do documentário, reproduzindo as reportagens sobre os crimes praticados por Lebach. Nesse sentido, no caso concreto $\left(C_{1}\right)$, o princípio da personalidade $\left(P_{2}\right)$ deveria preponderar sobre a liberdade de radiofusão $\left(P_{1}\right)$, visto que uma notícia repetida $\left(T_{1}\right)$, sem interesse atual pela informação $\left(T_{2}\right)$ sobre um crime grave cometido $\left(T_{3}\right)$ e que poderia produzir prejuízo à ressocialização de Lebach $\left(\mathrm{T}_{4}\right)$, seria proibida $(\mathrm{ORx})$ a partir dos Direitos Fundamentais. ${ }^{25}$ Considerando a Fórmula de Peso, seria possível dizer que a exibição do documentário implicaria uma plausível (senão provável) severa violação ao direito de proteção à personalidade, o que não se justificaria pela plausível leve ou média satisfação ao direito de liberdade de informação.

Ou seja, de forma lógica:

$$
\begin{aligned}
& (\mathrm{Tx} \rightarrow \mathrm{ORx}) \\
& \left(\mathrm{C}^{1} \mathrm{x} \rightarrow \mathrm{Tx}\right) \\
& \left(\mathrm{P}_{2} \mathrm{P} \mathrm{P}_{1}\right) \mathrm{C}_{1} \\
& \mathrm{C}_{1}\left(\mathrm{~T}_{1} \text { e } \mathrm{T}_{2} \text { e } \mathrm{T}_{3} \text { e } \mathrm{T}_{4}\right) \\
& \mathrm{GP}_{21} \mathrm{C}=\underline{\mathrm{IP}}_{2} \underline{\mathrm{C}(s)-\mathrm{SP}_{2}} \underline{\mathrm{C}(p)} \\
& \mathrm{WP}_{1} \mathrm{C}(m)-\mathrm{SP}_{1} \mathrm{C}(p)
\end{aligned}
$$

As formulações lógicas apresentadas por Robert Alexy foram construídas a partir dos casos julgados pelo Tribunal Federal Constitucional alemão. Outro caso explorado pelo autor foi o Cannabis, cuja decisão poderia ser considera emblemática na utilização da "Fórmula de Peso". A questão discutida era sobre a possibilidade de criminalização da fabricação, comercialização, disseminação e aquisição de produtos derivados da cannabis e se esta seria compatível com a liberdade de ação e pessoal (BVerfGE 90, 145). A dúvida seria a seguinte: a liberação da cannabis não seria um meio menos gravoso do que a proibição em relação à liberdade, podendo afastar o uso da droga e seu comércio ilegal? Diante dessa

25 ALEXY, Robert. Teoria dos Direitos Fundamentais. p. 102. 
indefinição, o Tribunal Federal Constitucional alemão decidiu pela adequação e necessidade da medida proibitiva. Para além, essa decisão poderia ser justificada também por meio da lei de sopesamento epistêmica. Dessa maneira, o tribunal teria decidido pela validade da criminalização, pois a incerteza sobre a liberação do uso da cannabis seria uma razão forte o bastante para justificar a intervenção nos direitos de liberdade envolvidos.

Tem-se, portanto, como indiscutível a relação existente entre a subsunção e o sopesamento. Essa afirmação se funda na sustentação de Alexy que a subsunção está presente no início e ao final da aplicação dos princípios jurídicos. Explicase: Início, pois seria possível subsumir os princípios jurídicos envolvidos em tensão por decorrência do caso concreto. Ao final, a subsunção seria a marca da aplicação lógica da regra de precedência condicionada construída entre os princípios jurídicos para aquele exclusivo caso concreto. ${ }^{26}$

Apelando-se a Gavião Filho, fica claro que a "Fórmula de Peso" pensada por Robert Alexy implicaria a atribuição de graus diferentes ao processo de sopesamento entre princípios jurídicos colidentes, colocando em evidência questões como: a intensidade de intervenção, o peso abstrato, a certeza das premissas, a importância de realização. ${ }^{27}$

Todavia o sopesamento não poderia ser tomado como um ato isolado de aplicação do Direito. Isso porque a sua validade dependeria do uso de razões que pudessem amparar conclusões quanto às questões indicadas. Para tanto, entende que o uso dessas razões somente poderia ser possível num entendimento global do ordenamento jurídico e da forma que diferentes casos são resolvidos. Isto é, o sopesamento seria dependente do uso de razões sobre as questões jurídicas e fáticas, algo somente possível, como será apresentado neste trabalho, por meio da "operação de comparação". Seria, portanto, pela análise comparativa de razões entre casos semelhantes, e diferentes, que a aplicação do Direito se justificaria. Por esse motivo, seria imperativo se conhecer a terceira operação de aplicação do Direito proposta por Robert Alexy: analogia ou comparação entre casos.

26 ALEXY, Robert. Two or Three. In: BOROWSKI, Martin. On the Nature of Legal Principles. ARSP-Beiheft 119 (Franz Steiner: Stuttgart, 2010), p. 11.

27 GAVIÃO FILHO, Anizio Pires. Colisão de direitos fundamentais, argumentação e ponderação. p. 283. 


\section{ANALOGIA OU COMPARAÇÃO ENTRE CASOS: A TERCEIRA OPERAÇÃO NA ADJUDICAÇÃO}

Será que as operações de aplicação do Direito envolvem apenas subsunção e sopesamento? Não seria possível imaginar outra forma de aplicação do Direito? Qual seria? Por ocasião do lançamento da obra em homenagem à teoria de Arthur Kaufmann sobre o processo de decisão judicial, Robert Alexy apresenta um esquema lógico que implicaria o reconhecimento de uma terceira forma de aplicação do Direito. Ela seria a analogia ou comparação entre casos. ${ }^{28}$

Especula-se que a justificação para a necessidade do estudo proposto pelo autor estaria no fato de ter passado a jurisdição constitucional a ocupar um papel de destaque para a implementação dos reclames democráticos, principalmente, a proteção e a concretização dos direitos fundamentais. Esse posicionamento pode ser reconhecido a Alexy quando reclama o poder da jurisdição constitucional como representante argumentativo do povo. ${ }^{29}$

Considerando isso, as decisões proferidas pela jurisdição constitucional passam a ganhar status diferenciado como fonte do Direito, exigindo, mesmo nos países marcados pela tradição da civil law, o seu respeito na condição de precedente judicial ${ }^{30}$. Nesse sentido, Bustamante afirma a função que os precedentes judiciais assumem na argumentação jurídica, mesmo naquelas culturas típicas da civil law, já que são capazes de prover critérios ou diretrizes para a interpretação e justificação do Direito. ${ }^{31}$

28 ALEXY, Robert. Two or Three. p. 9-18.

29 ALEXY, Robert. Ponderação, jurisdição constitucional e representação. In: ALEXY, Robert. Constitucionalismo discursivo. Trad. Luís Afonso Heck. Porto Alegre: Livraria do Advogado Editora, 2007, p. 163-165.

30 Embora seja possível distinguir entre duas espécies de precedentes tomados pela tradição jurídica brasileira - senão continental, quais sejam, persuasivos e vinculantes, o caráter dos precedentes assume a condição de razão que deve ser levada em consideração na argumentação jurídica. Cf. RAMIRES, Maurício. Crítica à aplicação de precedentes no Direito Brasileiro. Porto Alegre: Livraria do Advogado Editora, 2010, p. 66-67. Discutindo as influências, divergências e convergências entre as tradições da civil law e common law Cf. STRECK, Lenio Luiz; ABBOUD, Georges. O que é isto - o precedente judicial e as súmulas vinculantes? Porto Alegre: Livraria do Advogado Editora, 2013.

31 BUSTAMANTE, Thomas da Rosa. Finding Analogies between Cases: On Robert Alexy's Third Basic Operation in the Application of Law. In: On the Philosophy of Precedent, Proceedings of the 24th IVR World Congress. Mar 2012, p. 66. 
Consequentemente, tanto as proposições normativas decorrentes da produção legislativa quanto os precedentes acabam sendo fontes de referência à aplicação do Direito pelos juristas. Coloca-se em evidência, portanto, o questionamento de Robert Alexy sobre a terceira forma de operação jurídica - analogia ou comparação, em que é exigido do intérprete a análise de subsunções e sopesamento anteriores como pontos de partida para estabelecer consequências jurídicas em casos similares.

Ou seja, a operação jurídica da analogia ou comparação entre os casos seria útil por armar o intérprete de razões possíveis para requerer consequências jurídicas iguais ou diferentes, respectivamente, procurando dar efetividade ao tratamento isonômico de qualquer sistema jurídico coerente.

Essa ideia já foi esboçada por Alexy em outra oportunidade. Isso porque, na obra Teoria da Argumentação Jurídica, Robert Alexy procurou apresentar a noção de analogia como recurso argumentativo específico ao Direito. Seria a analogia, o argumentum a contrario, o argumentum a fortiori e o argumentum ad absurdum espécies de argumentos jurídicos considerados como especiais. ${ }^{32}$

Todavia a comparação de casos, ou analogia, deveria ser qualificada como um esquema operacional de aplicação do Direito, pois teria a característica de reunir os mesmos requisitos implementados pelas outras duas formas assim consagradas. É dizer, portanto, que tanto quanto a subsunção e o sopesamento, a comparação poderia ser vista como uma operação de aplicação do Direito que sempre seria seguida para estabelecer equivalências ou distinções entre os casos jurídicos. Assim, a sua condição de operação básica de aplicação do Direito decorreria de três atributos, quais sejam: formal, necessário e específico. ${ }^{33}$

A condição formal do esquema estaria ligada à possibilidade de construir uma estrutura lógica que orientasse a sua aplicação. A necessidade implicaria o reconhecimento de constrição da forma lógica como orientadora na resolução de todos os casos jurídicos. E a especificidade determinaria o reconhecimento

32 ALEXY, Robert. Uma teoria da argumentação jurídica. In: ALEXY, Robert. Teoria da argumentação jurídica: a teoria do discurso racional como teoria da fundamentação jurídica. Trad. Zilda Hutchinson Schild Silva. 2. ed. São Paulo: Landy Editora, 2005, p. 268.

ALEXY, Robert. Two or Three. p. 10. 
da forma específica, subsunção, sopesamento ou analogia, como operações jurídicas específicas a cada caso contingencial de aplicação do Direito.

Ainda sobre a especificidade, sempre que as discussões envolvessem a aplicação das regras jurídicas, utilizar-se-ia o esquema da subsunção. Quando os problemas jurídicos envolvessem a tensão entre princípios jurídicos, recorrer-se-ia ao sopesamento. Agora, seria possível reconhecer à analogia um comportamento assim? Esse foi o desafio posto por Alexy.

Para resolver esse imbróglio, Alexy parece se valer da exigência argumentativa do Direito.Isto é, embora seja possível construir esquemas lógicos que representam a operação de aplicação do Direito - nos casos de subsunção e sopesamento -, a racionalidade ou legitimidade ${ }^{34}$ dessas operações jurídicas estaria condicionada à capacidade argumentativa do jurista.

E mais, especula-se que o recurso à analogia ou à comparação de casos seria o modo da ordem jurídica lidar com a necessidade de construção de novas proposições normativas a partir de uma base de proposições jurídicas já saturadas. Portanto a analogia ou a comparação permitiria a inserção de novos dados ao sistema jurídico.

Das operações reconhecidas na aplicação do Direito, cuja formulação lógica corresponde ao modelo de subsunção - já se viu que o próprio sopesamento visaria à criação de uma regra a ser subsumida, construída sobre a lógica se... -, a analogia seria diferente, pois deveria estabelecer uma relação com a ordem jurídica por meio do princípio (lógico) da universalidade ou da igualdade. ${ }^{35}$

Assim, a regra ou proposição jurídica saturada ${ }^{36}$ na ordem jurídica serviria de ponto de apoio ao estabelecimento de semelhanças e diferenças com os 34 Não se pode esquecer de que a legitimidade do Direito, para Robert Alexy, decorre da capacidade da proposição jurídica ser fundamentada argumentativamente. Isso fica claro no Prefácio da sua obra Teoria da Argumentação Jurídica que, com olhos na decisão do Tribunal Federal Constitucional alemão BVerfGE 34, 269 (287), procurou fundar teoricamente a afirmação de que as decisões judiciais devem ser argumentações racionais para serem válidas. Cf. ALEXY, Robert. Uma teoria da argumentação jurídica. p. 5.

35 ALEXY, Robert. Uma teoria da argumentação jurídica. p. 271.

36 A nocão de saturação é relevante à argumentação jurídica, porque institui dogmas a priori como produtos de consensos institucionais sobre o alcance normativo das normas jurídicas. Apenas ilustrativamente, a saturação das proposições judicias pode se dar por reiteradas decisões sobre determinadas questões apoiadas ao consenso dogmático sobre a correção dessas decisões. 
casos apreciados, visto que uma das máximas do Direito seria fazer com que "os fatos hipotéticos semelhantes do ponto de vista jurídico tivessem as mesmas consequências jurídicas". ${ }^{37}$

Esse é o elemento central do pensamento analógico ou comparativo. Como dito anteriormente, restava traduzir a operação analógica numa estrutura lógica que pudesse reunir os qualificativos da formalidade, da necessidade e da especificidade. Para tanto, Alexy se vale da seguinte fórmula:

$A_{1}$ : Em cada caso $C_{i}$, cada caso $C_{j}$ pode apresentar o argumento que $C_{i}$ compartilha com $\mathrm{C}_{\mathrm{j}}$ os elementos $\mathrm{F}_{1^{j}}, \ldots, \mathrm{F}_{\mathrm{n}}^{\mathrm{j}}$, e assim $\mathrm{C}_{\mathrm{i}}$ por essas razões e porque elas determinam a regra $\mathrm{F}_{1^{\prime}}, \ldots, \mathrm{F}_{\mathrm{n}}^{\mathrm{j}} \rightarrow \mathrm{Q}$, deve ser tratado, como $\mathrm{C}_{\mathrm{j}}$, como o mesmo efeito $\mathrm{Q}{ }^{38}$

$A_{2}$ : Em cada caso que é apresentado um argumento adicional a $A_{1^{\prime}}$ duas pretensões surgem:

$A_{2.1}$ : Pretendendo-se diferenciar $C_{i}$ pelos elementos $F_{1}^{i}, \ldots, F_{n}^{i}$ de $C_{j^{\prime}}$ então, $C_{i}$ por essa razão e porque existem razões para a regra $\mathrm{F}_{1}^{\mathrm{i}}, \ldots$, $\mathrm{F}_{\mathrm{n}}^{\mathrm{i}} \rightarrow \neg \mathrm{Q}$, deve ser tratado de forma distinta à $\mathrm{C}_{\mathrm{j}^{\prime}}$ produzindo o efeito $\neg \mathrm{Q}$.

$A_{2.2}$ : Pretendendo-se que $C_{i}$ compartilhe com $C_{k}$ os elementos $F_{1, \ldots,}^{k} F_{n^{\prime}}^{k}$ e que $C_{i}$, por essa razão e porque existem razões para a regra $F_{1}^{k}{ }_{1}, \ldots, F_{n}^{k}$ $\rightarrow \neg \mathrm{Q}$, deve ser tratado, como $\mathrm{C}_{\mathrm{k}^{\prime}}$ produzindo o efeito $\neg \mathrm{Q}$.

Especula-se que as referidas construções lógicas procuram dar conta da relação de aplicação do Direito. Viu-se que, para Alexy, o sopesamento entre princípios jurídicos serviria à criação de uma regra, aplicável no esquema lógico do tudo ou nada. Portanto, preenchida a hipótese fática, as regras se apresentariam como razões definitivas para determinado dever-ser. Ainda, para que uma regra deixasse de ser aplicada, dever-se-ia reconhecer (ou introduzir) uma cláusula de exceção à sua aplicação ${ }^{39}$.

37 ALEXY, Robert. Uma teoria da argumentação jurídica. p. 271.

38 ALEXY, Robert. Two or Three. p. 17.

39 Operação essa que se valia do sopesamento existente entre os princípios jurídicos envolvidos no caso. Ou seja, o princípio jurídico que desse suporte à regra cederia, dando lugar ao princípio jurídico contrário, num dado caso concreto, o que permitiria, nesse novo sopesamento, a introdução de uma exceção à regra. Cf. ALEXY, Robert. Teoria dos Direitos Fundamentais. p. 98. 
Tomando o modelo operacional das regras, a analogia proposta por Robert Alexy procura traduzir numa fórmula lógica como, ou melhor, que razões seriam passíveis para se requerer o afastamento da regra, a introdução de exceções ou a construção de uma nova regra a partir de princípios jurídicos. Para tanto, subsunção, sopesamento e analogia teriam uma ligação metodológica.

Para apresentar de forma exemplar a analogia ou comparação entre casos, Alexy recorre ao exemplo utilizado por Hart sobre a proibição da entrada de veículos no parque. Ou seja, na condição imperativa: $\left(R_{1}\right)$ "é proibido o trânsito de veículos no parque". ${ }^{40}$ Normas como essa podem ser tanto derivadas de fontes legislativas como jurisprudenciais. Especula-se que, na condição de fontes jurisprudenciais, essas normas podem derivar de sopesamentos.

Poderia um automóvel transitar no parque? Decidindo essa questão, o tribunal poderia proibir o trânsito do automóvel com base na $R_{1}$. Ou seja: $\left(R_{2}\right)$ "automóvel não pode transitar no parque". Essa norma derivaria da fonte jurisprudencial.

Outro caso surge questionando a possibilidade de ingresso de bicicletas no parque. Ao apreciar isso, o tribunal se posicionou no sentido de que o caso não se submeteria à $R_{1}$

O afastamento da regra se daria pelas seguintes razões: andar de bicicleta seria uma atividade recreacional protegida pelo direito de liberdade, não causando barulho nem poluição. A norma poderia ser assim expressada: $\left(R_{3}\right)$ "bicicletas podem transitar no parque". O efeito seria construir uma exceção à aplicação da regra $R_{1}$.

Ainda outro caso é submetido à apreciação, qual seja: "motor scooter" pode transitar no parque, já que ela seria similar à bicicleta? Os argumentos eram: (1) tanto andar de bicicleta como de "motor scooter" seriam atividades similares; (2) também seria uma atividade recreacional; (3) o risco aos pedestres seriam quase os mesmos. Os contra-argumentos foram que a motor scooter seria muito mais parecida com um automóvel, visto que ambos produziriam barulho e poluição. Como resolver considerando esses argumentos? Já existe uma regra que resolva a questão? A resposta de Alexy provavelmente seria negativa. Aí, dever-se-ia recorrer aos princípios jurídicos. A produção da regra para esse caso deveria

40 ALEXY, Robert. Two or Three. p. 12. 
surgir do sopesamento entre os princípios jurídicos envolvidos ${ }^{41}$.

No caso da motor scooter, a similitude com a bicicleta se daria pelo fato de compartilhar questões como a atividade recreacional e o baixo perigo aos pedestres, que suportariam o apelo ao princípio da liberdade. A decisão considera que, em se tratando de atividade recreacional, proporcionando baixo perigo aos pedestres, o princípio da liberdade exigiria a permissão de trânsito no parque. Num esquema lógico, Alexy representa essa condição: $\left(R_{4}\right) \mathrm{F}_{1}^{j} \wedge \mathrm{F}_{2} \rightarrow \mathrm{Q}$. Ainda, a comparação seguiria, também, o esquema da analogia $A_{1^{\prime}}$ explicitando as razões decorrentes do princípio da liberdade.

Todavia o opositor diria que a diferença estaria no fato de a motor scooter possuir motor, que provocaria barulho e poluição, o que não permitiria a sua comparação à bicicleta. Seria possível construir a seguinte proposição lógica: $\left(R_{5}\right) F_{1}^{i} \rightarrow \neg Q$. A comparação sugerida seguiria o esquema lógico da analogia proposta pelo autor na regra $A_{2.1}$. Ainda, outra variação seria possível: a motor scooter guardaria semelhança com o veículo por possuir motor e não poderia ter o seu trânsito permitido no parque. Seria assim: $\left(\mathrm{R}_{6}\right) \mathrm{F}_{1}^{\mathrm{k}} \rightarrow \neg \mathrm{Q}$.

Decidiu-se, a partir da comparação proposta, que a motor scooter não poderia ingressar no parque, visto que: $\left(R_{4}^{\prime}\right)$ "veículos que sirvam à atividade recreacional $\left(\mathrm{F}_{1}{ }_{1}\right)$ e não representam grande perigo aos pedestres $\left(\mathrm{F}_{2}{ }_{2}\right)$ poderiam ingressar no parque $(\mathrm{Q})$ ". Esse problema, que envolveria a colisão dos princípios jurídicos da liberdade de ação $\left(P_{1}\right)$ e do silêncio e do sossego no parque $\left(P_{2}\right)$, poderia ser formalizado na seguinte condição:

$$
\begin{aligned}
& \left(P_{2} \mathbf{P} P_{1}\right) C \\
& \left(P_{2} \mathbf{P} P_{1}\right) C_{i .} \\
& \left(P_{2} \mathbf{P} P_{1}\right) F_{1 .}^{i} \\
& \left(P_{2} \mathbf{P} P_{1}\right) F_{1}^{j} \wedge F_{2}^{j} \wedge F_{1}^{i} .
\end{aligned}
$$

41 Logo, a partir da limitação da previsão fática da regra, tanto a construção da exceção quanto a criação de nova regra se submeteriam à comparação de razões. Razões essas que somente poderiam ser consideradas porque derivadas de algum princípio jurídico suporte da produção legislativa ou judicial. É claro que, diante de um novo caso a ser apreciado, novos princípios jurídicos poderiam se colocar em conflito, o que exigiria um novo juízo de sopesamento das razões de ambas as partes. 
A discussão sobre as razões que suportam ou não as questões relevantes para a aplicação das regras evidenciam a dependência existente entre os elementos fáticos considerados nos comandos normativos. Portanto, comparar similaridades e diferenças serviria para reconhecer as questões relevantes que dariam suporte aos comandos normativos anteriores e que não poderiam ser descartados na discussão de um novo caso concreto. ${ }^{42}$

É possível que se observe que a analogia colocaria em evidência os fatos relevantes considerados nas decisões anteriores com base em subsunções e sopesamentos da seguinte forma: seriam razões que suportariam a aplicação da norma anterior. ${ }^{43}$ Seria possível dizer, e o apoio é Alexy, que os fatos relevantes seriam razões para adoção de consequências similares e diferenciadas numa caracterização de princípio jurídico. Portanto a (fórmula da) analogia acabaria apresentando a conexão existente entre casos, regras e princípios jurídicos. ${ }^{44}$

Bustamante vai endossar esse posicionamento, afirmando que a analogia serviria para justificar o sopesamento entre os princípios que suportam uma norma precedente e aqueles princípios jurídicos que devem ser considerados pela análise de um novo caso concreto, concentrando-se, todavia, nas questões fáticas relevantes destacadas. ${ }^{45}$ Contudo esse destaque às questões fáticas relevantes é criticado por Bustamente, porque ofuscaria a argumentação por meio dos princípios jurídicos balanceados. ${ }^{46}$

Falar em analogia (ou do esquema lógico da analogia desenvolvido por Alexy)

42 Essa consideração aos casos anteriores seria uma forma de reforçar a correção do posicionamento. Portanto, quando se fala em metodologia em mente, não se pode deixar de compreender a relação entre esse posicionamento metodológico e a sua associação à correção da interpretação jurídica. Cf. TOMAZ DE OLIVEIRA, Rafael. Método jurídico e interpretação do Direito: reflexões programáticas sobre a concretização dos Direitos Coletivos. Revista Brasileira de Direito. Passo Fundo, v. 9, n. 2, jul-dez. 2013, p. 100.

43 ALEXY, Robert. Two or Three. p. 14.

44 ALEXY, Robert. Two or Three. p. 14.

45 BUSTAMANTE, Thomas da Rosa. Finding Analogies between Cases: On Robert Alexy's Third Basic Operation in the Application of Law. In: On the Philosophy of Precedent, Proceedings of the 24th IVR World Congress. Mar 2012. p. 5.

46 Cf. BUSTAMANTE, Thomas da Rosa. Finding Analogies between Cases: On Robert Alexy's Third Basic Operation in the Application of Law. p. 6. Discorda-se do posicionamento de Bustamente, porque se entende ser indissociável a compreensão de princípios jurídicos, e sopesamentos ( $\mathrm{sic}$ ), e a compreensão da sua concreta relação com as questões fáticas relevantes. O que poderia ser considerado, numa especulação, como o poder normativo da facticidade. 
seria exigência na aplicação do Direito que, na disputa de similaridade entre casos, apresentaria as razões que suportariam as normas anteriores, colocando-as em sopesamento ${ }^{47}$ com outras razões. Para tanto, quando se fizesse o balanceamento entre princípios, estar-se-ia selecionando questões relevantes decorrentes deles como razões para determinada consequência jurídica. ${ }^{48}$

Conclui-se, portanto, que a fórmula da analogia proposta por Robert Alexy, e suas derivações lógicas $\left(A_{1^{\prime}} A_{2^{\prime}} A_{2.1,} A_{2.2 .}\right)$, teria como função apresentar um esquema lógico de qualidade formal, necessária e específica, que expresse o modus operandi da aplicação do Direito mediante a comparação de casos e o seu corolário argumentativo. ${ }^{49}$

O Direito teria evidenciado, nessa proposta de Alexy, um âmbito interpretativo que envolveria estabelecer relações positivas, negativas e diferenciadoras entre casos, baseados em fundamentos sobre questões relevantes, possibilitando a determinação do lugar normativo da resolução jurídica de cada caso como fonte do Direito. ${ }^{50}$

\section{CONSIDERAÇÕES FINAIS}

O presente trabalho mostra como que o princípio da proporcionalidade ganha contornos (metodo)lógicos no pensamento de Robert Alexy, o que visa contribuir à discussão do referido recurso como algo isolado ou dissociado do contexto teórico proposto pelo autor alemão. Nesse sentido, a contribuição que se pretende é apresentar elementos para que se reclame maior rigor dogmático, conceitual e lógico à aplicação do princípio da proporcionalidade. Aliás, mostrouse que a proporcionalidade serve, na proposta teórica de Robert Alexy, como critério indicado dos limites de controle à discricionariedade do legislador.

47 Essa seria a conexão existente entre a comparação entre casos e o sopesamento. É dizer que a comparação entre os casos permitiria colocar em discussão as questões ou os fatores relevantes decorrentes de cada um dos princípios jurídicos envolvidos. Cf. ALEXY, Robert. Two or Three. p. 15.

48 ALEXY, Robert. Two or Three. p. 15.

49 ALEXY, Robert. Two or Three. p. 18.

50 ALEXY, Robert. Two or Three. p. 18. 
Elucida-se também que, para o autor alemão, a subsunção e o sopesamento estão intimamente ligados na aplicação do Direito. Como novidade, portanto, explorou-se a conexão entre as duas formas lógicas anteriores à comparação ou analogia. Isso porque, especula-se, o Direito não pode mais ser pensando sem integrar a jurisprudência como sua fonte, principalmente, aquelas decisões proferidas pelos tribunais competentes pelo controle de constitucionalidade. Consequentemente, a fórmula da comparação apresentada indica um corolário lógico que orienta a consideração de razões relevantes a serem sopesadas em processos de verificação e determinação da relação de precedência entre princípios jurídicos, visando, nos termos da teoria de Alexy, à constituição de normas de direito fundamental aditadas ou atribuídas ao texto constitucional.

Todavia a formulação de esquemas lógicos - mesmo que a formulação e explicação deles sirvam para apurar a compreensão sobre as formas de aplicar o Direito para Robert Alexy - em nada acaba contribuindo à discussão sobre como as decisões que se valem da subsunção, do sopesamento e da analogia (comparação de casos) são consideradas legítimas. A legitimidade ou não da decisão decorre, já a partir do próprio Alexy, da argumentação prático-jurídica que sustente racionalmente as decisões judiciais. Ou seja, que apresentem razões aceitáveis no suporte da decisão proferida. Assim, consequentemente, não se pode descurar que, para Alexy, o nível lógico-formal ou operacional de aplicação do Direito serve de esquema a priori que organiza a fundamentação a posteriori da legitimidade - aceitação - racional da decisão judicial. É nessa imbricação - entre lógica e argumentação - que a correção da decisão judicial poderia ser aferida.

REFERENCIAS

ALEXY, Robert. Two or Three. In: BOROWSKI, Martin. On the Nature of Legal Principles. ARSP-Beiheft 119 (Franz Steiner: Stuttgart, 2010), p. 9 -18.

ALEXY, Robert. Teoria dos Direitos Fundamentais. Trad. de Virgilio Afonso da Silva. São Paulo: Malheiros Editores, 2008.

ALEXY, Robert. Direito constitucional e direito ordinário - jurisdição constitucional e jurisdição 
especializada. In: ALEXY, Robert. Constitucionalismo discursivo. Tradução Luís Afonso Heck. Porto Alegre: Livraria do Advogado Editora, 2007, p. 71-92.

ALEXY, Robert. Ponderação, jurisdição constitucional e representação. In: ALEXY, Robert. Constitucionalismo discursivo. Trad. Luís Afonso Heck. Porto Alegre: Livraria do Advogado Editora, 2007.

ALEXY, Robert. Uma teoria da argumentação jurídica. In: ALEXY, Robert. Teoria da argumentação jurídica: a teoria do discurso racional como teoria da fundamentação jurídica. Trad. Zilda Hutchinson Schild Silva. 2. ed. São Paulo: Landy Editora, 2005.

ALEXY, Robert. On Balancing and Subsumption. A Strctural Comparison. Ratio Juris, v.16. n. 4. Dec 2003, p. 433-449.

BUSTAMANTE, Thomas da Rosa. Finding Analogies between Cases: On Robert Alexy's Third Basic Operation in the Application of Law. In: On the Philosophy of Precedent, Proceedings of the 24th IVR World Congress. Mar 2012.

BUSTAMANTE, Thomas da Rosa. Principles, Precedents and Their Interplay in Legal Argumentation: How to Justify Analogies Between Cases. In: BOROWSKI, Martin. On the Nature of Legal Principles. ARSP-Beiheft 119 (Franz Steiner: Stuttgart, 2010), p. 63 -78

GAVIÃO FILHO, Anizio Pires. Colisão de dirietos fundamentais, argumentação e ponderação. Porto Alegre: Livraria do Advogado Editora, 2011.

RAMIRES, Maurício. Crítica à aplicação de precedentes no Direito Brasileiro. Porto Alegre: Livraria do Advogado Editora, 2010.

TOMAZ DE OLIVEIRA, Rafael. Método jurídico e interpretação do Direito: reflexões programáticas sobre a concretização dos Direitos Coletivos. Revista Brasileira de Direito. Passo Fundo, v. 9, n. 2, jul-dez. 2013, p. 90-129.

STRECK, Lenio Luiz; ABBOUD, Georges. $\mathbf{O}$ que é isto - o precedente judicial e as súmulas vinculantes? Porto Alegre: Livraria do Advogado Editora, 2013.

Recebido em: ago/2015

Aprovado em: out/2015 